\title{
Criação de um curso a distância de Introdução a Eletrônica Digital na Rede Social Educacional REDU
}

\author{
Arthur Felipe Thamay ${ }^{1}$, Adriano Santos ${ }^{1}$. \\ ${ }^{1}$ Departamento de Computação - Centro de Ciência e Tecnologia \\ Universidade Estadual da Paraíba (UEPB) - Campina Grande, PB - Brazil \\ felipethamay@hotmail.com, adriano.nego@gmail.com
}

\begin{abstract}
Distance education is becoming a very affordable means of learning, thanks to advances in Information Technology and Communication. This article describes the creation of a distance course in platform social education REDU, addressing the theme "Introduction to Digital Electronics". The objective of the course is to help beginner students of IT courses as Telematics, Information Systems, Computer Science.

Resumo. A educação a Distância tem se tornando um meio de aprendizagem muito acessivel, graças aos avanços das Tecnologias da Informação e Comunicação. Este artigo descreve a criação de um curso a distância na plataforma social educacional REDU, abordando o tema "Introdução a Eletrônica Digital”. O objetivo principal do curso é auxiliar os alunos iniciantes dos cursos de TI como Telemática, Sistemas de informação, Ciências da Computação.
\end{abstract}

\section{INTRODUÇÃO}

A educação à distância (EAD), é uma modalidade de ensino-aprendizagem em que o aluno e o professor não necessariamente precisam estar em um mesmo ambiente físico. Baseado nessas novas tendências surgiu o ambiente virtual de aprendizagem chamado REDU, um serviço de plataforma de aprendizagem nas nuvens. Apresenta-se como uma solução para ordenar e resignificar a comunicação e a prática educativa entre pais, alunos, professores e instituição promovendo a criação de uma comunidade integrada (GOMES, ROLIM, SILVA; 2012).

Este trabalho mostra o curso de Introdução à Eletrônica Digital criado na plataforma REDU aplicado no período de julho a agosto de 2013, com o intuito de auxiliar os alunos iniciantes dos cursos de tecnologia.

\section{FUNDAMENTAÇÃO TEÓRICA}

As redes sociais virtuais na educação começam a ser exploradas como meio para auxiliar professores e alunos no processo ensino-aprendizagem. Podem ser usadas como ferramentas de uso pedagógico para o ensino e aprendizagem em grupo (QUEIROZ, 2011), são ideais para a formação de grupos com interesses comuns e o compartilhamento de conhecimentos, promovendo um ambiente propício para que ocorra o aprendizado colaborativo. 
Conforme Valente (1991, p. 16), “A implantação da informática na educação consiste basicamente de quatro ingredientes: o computador, o software educativo, o professor capacitado a usar o computador como ferramenta educacional e o aluno".

Pensando neste contexto surge então a proposta da rede social educativa REDU (Figura 1 e 2) um software social que representa um ambiente de aprendizagem e ensino que foi criado a partir da necessidade de ampliar o meio escolar e proporcionar uma maior interação entre os atores envolvidos (ABREU, 2011). Este ambiente incentiva a participação direta de todos os envolvidos, auxiliando a troca de informações entre os alunos e os professores fazendo com que todos se sintam parte constituinte do conhecimento que está sendo produzido. Nesta plataforma estão presentes vários objetos de aprendizagem, vídeo-aulas, artigos, documentos, exercícios, espaço para discussões, comunicação em tempo real entre outros.

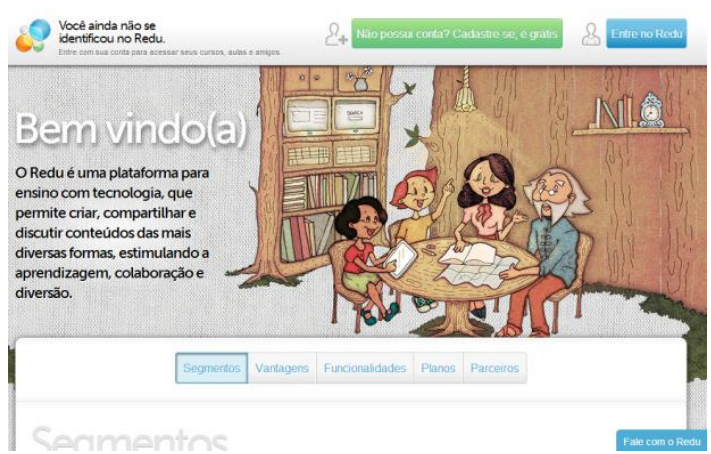

Figura 1. Página principal

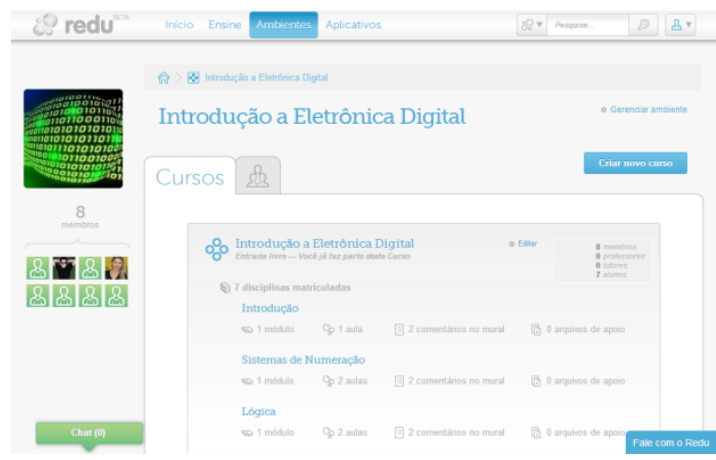

Figura 2. Página do curso

\section{DISCUSSÃO}

Dados atuais mostram que os mais de 200 milhões de habitantes que compõem o cenário brasileiro em sua atualidade, apenas 7 milhões de brasileiros buscam formação pela internet (CGI, 2010). Diante disso, o uso de redes sociais na educação serve como impulso na transformação dos paradigmas educacionais, buscando cada vez mais socializar o ensino ao ambiente tecnológico atingindo todas as classes sociais.

Desde que foi citado na LDB Lei $\mathrm{n}^{\circ}$ 9.394, aprovada em vinte de dezembro de 1996, a EAD tem se fortalecido no Brasil. O Art. 80 atribui ao Poder Público o papel de "incentivar o desenvolvimento e a veiculação de programas de ensino a distância, em todos os níveis e modalidades de ensino, e de educação continuada".

Dados atualizados do blog do REDU afirmam que no mês de Junho de 2013 o site atingiu mais de 20.000 usuários cadastrados após seu lançamento no mês de maio de 2012. Isso mostra que a rede social como intermédio para educação é uma proposta promissora.

As disciplinas de introdução à computação dos cursos de TI como Telemática, Ciências da computação, Sistemas de informação, entre outros. Utilizam tópicos relacionados à eletrônica digital. Vendo tal necessidade, o curso foi desenvolvido para auxiliar os alunos iniciantes.

Nesta perspectiva, o trabalho apresenta uma proposta de curso a distancia, onde o tema é "Introdução à eletrônica digital". Com isso, abordando assuntos pertinentes 
como: Introdução, Sistemas analógicos e digitais, Números binários, Lógica, Circuitos digitais, Multiplexadores e Demultiplexadores e Introdução a microcontroladores.

\subsection{Introdução}

Este tópico aborda a historia da eletrônica e seus princípios fundamentais bem como suas aplicações nos dias atuais.

\subsection{Sistemas analógicos e digitais}

Este tópico traz o conceito de eletrônica analógica e eletrônica digital. É importante inicialmente diferir os dois conceitos para que isso fique claro. Na eletrônica analógica o seu valor pode variar durante certo tempo, já na eletrônica digital apenas há duas variáveis num circuito durante o funcionamento do equipamento.

\subsection{Números binários}

Este módulo trabalha com números binário, decimal, octal e hexadecimal e as conversões entre base.

\subsection{Lógica}

Trabalha com álgebra booleana e suas operações. A álgebra booleana é uma álgebra que traduz os sinais em expressões matemáticas. Para isso, é preciso definir cada sinal elementar por variáveis lógicas e seu processamento por funções lógicas. Certos métodos (tabela da verdade) permitem definir operações que queremos realizar e, traduzir o resultado em uma expressão algébrica.

\subsection{Circuitos digitais}

Abordando os conceitos de portas logicas. A importância dessas portas lógicas está no fato de representarem os elementos básicos de construção da maioria dos circuitos digitais práticos.

\subsection{Multiplexadores e Demultiplexadores}

Este modulo aborda o conceito de multiplexadores e demultiplexadores, onde pode-se observar que são sistemas digitais que processam informações de diversas formas, funcionando como conversores série/paralelo e vice versa

\subsection{Introdução a microcontroladores}

Este tópico faz uma introdução à microcontroladores e suas aplicações nos dias atuais. O microcontrolador foi consolidado como elo entre a eletrônica e a informática, sendo um chip de baixo custo e dotado de Inteligência programável, é cada vez mais comum encontrarmos projetos com esta tecnologia.

\section{RESULTADOS}

Foi aplicado um questionário online contendo dez questões de múltipla escolha, onde os resultados foram: 
Tabela 1 - Acertos e erros referentes ao exercício.

\begin{tabular}{|l|l|l|}
\hline Alunos & Acertos & Erros \\
\hline Aluno 1 & 10 & 0 \\
\hline Aluno 2 & 7 & 3 \\
\hline Aluno 3 & 7 & 3 \\
\hline Aluno 4 & 9 & 1 \\
\hline Aluno 5 & 8 & 2 \\
\hline Aluno 6 & 6 & 4 \\
\hline Aluno 7 & 7 & 3 \\
\hline
\end{tabular}

As perguntas respondidas pelos alunos foram verificadas sua validade e confiabilidade pelo coeficiente de alfa Cronbach, onde se mede a correlação entre respostas em um questionário através da análise das respostas dadas pelos alunos, apresentando uma correlação média entre as perguntas. $\mathrm{O}$ coeficiente $\alpha$ é calculado a partir da variância dos itens individuais e da variância da soma dos itens de cada avaliador de todos os itens de um questionário que utilizem a mesma escala de medição (VIEIRA, 2013), conforme a Tabela 2 abaixo:

Tabela 2 - Dados agrupados referente ao exercício proposto

\begin{tabular}{|c|c|c|c|c|c|c|c|c|c|c|c|}
\hline & \multicolumn{9}{|c|}{ Item } & \multicolumn{1}{l|}{ Total } \\
\hline Alunos & $\mathbf{1}$ & $\mathbf{2}$ & $\mathbf{3}$ & $\mathbf{4}$ & $\mathbf{5}$ & $\mathbf{6}$ & $\mathbf{7}$ & $\mathbf{8}$ & $\mathbf{9}$ & $\mathbf{1 0}$ & $\mathbf{( \mathbf { T } _ { \mathbf { i } } )}$ \\
\hline $\mathbf{1}$ & 1 & 1 & 1 & 1 & 1 & 1 & 1 & 1 & 1 & 1 & 10 \\
\hline $\mathbf{2}$ & 1 & 0 & 1 & 1 & 1 & 1 & 0 & 1 & 0 & 1 & 7 \\
\hline $\mathbf{3}$ & 1 & 0 & 1 & 0 & 1 & 0 & 1 & 1 & 1 & 1 & 7 \\
\hline $\mathbf{4}$ & 1 & 1 & 1 & 1 & 1 & 1 & 0 & 1 & 1 & 1 & 9 \\
\hline $\mathbf{5}$ & 1 & 1 & 1 & 0 & 1 & 1 & 0 & 1 & 1 & 1 & 8 \\
\hline $\mathbf{6}$ & 1 & 0 & 1 & 1 & 1 & 0 & 0 & 1 & 0 & 1 & 6 \\
\hline $\mathbf{7}$ & 1 & 0 & 1 & 0 & 1 & 1 & 0 & 1 & 1 & 1 & 7 \\
\hline Média & $\mathbf{1}$ & $\mathbf{0 , 5 7}$ & $\mathbf{1}$ & $\mathbf{0 , 4 3}$ & $\mathbf{1}$ & $\mathbf{0 , 2 9}$ & $\mathbf{0 , 2 7}$ & $\mathbf{1}$ & $\mathbf{0 , 2 9}$ & $\mathbf{1}$ & \\
\hline Variância & $\mathbf{0}$ & $\mathbf{0 , 2 8 6}$ & $\mathbf{0}$ & $\mathbf{0 , 2 8 6}$ & $\mathbf{0}$ & $\mathbf{0 , 2 3 8}$ & $\mathbf{0 , 2 3 8}$ & $\mathbf{0}$ & $\mathbf{0 , 2 3 8}$ & $\mathbf{0}$ & \\
\hline
\end{tabular}

Calculamos o coeficiente de acordo com a Tabela 3, onde:

k: é o numero de itens (perguntas do exercício),

$\mathrm{S}_{\mathrm{i}} \wedge 2$ : é o somatório da variância dos itens

$\mathrm{S}_{\mathrm{t}} \wedge 2$ : é a variância da soma dos itens

$\alpha$ : Alfa de Cronbach

Tabela 3 - Calcula $\alpha$ de Cronbach

\begin{tabular}{|l|}
\hline$\alpha=\frac{k}{k-1}\left[1-\frac{\sum S i 2}{S \mathrm{t} 2}\right]$ \\
\hline$\alpha=\frac{10}{10-1}\left[1-\frac{1,0474}{1,9048}\right]$ \\
$\alpha \alpha=0,5$ \\
\hline
\end{tabular}

Hayes (1998) definiu a confiabilidade como o grau em que o resultado medido reflete o resultado verdadeiro, ou seja, quanto uma medida está livre da variância dos erros aleatórios.

Tabela 4- Classificação da confiabilidade a partir do coeficiente $\alpha$ de Cronbach

\begin{tabular}{|l|l|l|l|l|l|l|l|}
\hline Confiabilidade & Muito Baixa & Baixa & Moderada & Alta & Muito Alta \\
\hline Valor de $\alpha$ & $\alpha \leq 0,30$ & $0,30<\alpha$ & $0,60<\alpha \leq 0,75$ & $0,75<$ & $\alpha$ & $\alpha>0,90$ \\
& & $\leq 0,60$ & & & & $\leq 0,90$
\end{tabular}


De acordo com o grau de confiabilidade $\alpha$ de Cronbach, os resultados obtidos mostram baixa confiabilidade. Este trabalho foi um teste piloto, realizado em um curto espaço de tempo com poucas amostras envolvidas.

\section{CONSIDERAÇÕES FINAIS}

Esta pesquisa encontra-se em andamento, com os dados obtidos é possível ter uma base para realização de novos trabalhos voltados a cursos utilizando as TIC no ambiente educacional, e desta forma poder aproximar cada vez mais os professores e alunos a essa nova tecnologia, buscando sempre integrar o tecnológico ao ambiente de sala de aula, com recursos e objetivos mais amplos. Como foi observado, tivemos uma média de 7,71 acertos e 2,29 erros, ou seja, tivemos um aproveitamento de $77 \%$ dos 7 alunos avaliados. É possível concluir que aceitação foi satisfatória e que a proposta do curso oferece bases significativas para pesquisas posteriores.

\section{Referências}

ABREU, João Alberto Brito de. Análise das Práticas de Aprendizagem Colaborativas em Redes Sociais virtuais no Ensino Médio. 2011. 92 f. Universidade Federal de Pernambuco, Recife, 2011.

Brasil. Lei n 9.394, que estabelece as diretrizes e bases da educação nacional. Brasília, $1996 . \quad$ Disponível em URL: http://www.planalto.gov.br/ccivil_03/leis/19394.htm. Acesso em: 11 jul. 2013.

CGI. Comitê Gestor da Internet no Brasil. Censo 2010. Disponível em $<$ http://www.cgi.br $>$. Acesso em: 10 Julho 2013.

GOMES, A. S.; ROLIM, A. L. S. ; SILVA, W. M. . Educar com o Redu. 1. ed. Recife: Editora universitária da UFPE, 2012. v. 1. 104p.

HAYES, B. E. Measuring Customer Satisfaction: Survey design, use, and statistical analysis methods. Milwaukee, Wisconsin: ASQC Quality Press, 1998.

QUEIROZ, Tania Lucia de Araujo. Redes Sociais: A concepção dos professores sobre as possibilidades de uso na educação. 2011. 12 f. - Pontifícia Universidade Católica do Paraná, Curitiba, 2011.

REDU. Potencializando o talento das pessoas. Disponível em: $<$ http://tech.redu.com.br/>. Acesso em: 11 jul. 2013.

VALENTE, José Armando. Liberando a Mente: Computadores na Educação Especial. Gráfica da UNICAMP. Campinas, São Paulo, 1991.

VIEIRA, Sonia. Alfa de Cronbach. Disponível em: $<$ http://soniavieira.blogspot.com.br/2013/02/alfa-de-cronbach.html $>$. Acesso em: 09 ago. 2013. 